\title{
Study of the Dynamic Loading Impact on the Design of Pentices when Sinking Vertical Mine Shafts
}

\author{
Vladimir Pershin ${ }^{1}$, Aleksandr Kopytov ${ }^{1}$, Yuriy Fadeev ${ }^{1}$, and Ahmed $_{\text {Wetti }}{ }^{1}$
}

${ }^{1}$ T.F. Gorbachev Kuzbass State Technical University, 650000, 28 street Vesennyaya, Kemerovo, Russian Federation

\begin{abstract}
Based on the reconstruction project for Gorno-Shorsky branch of JSC "Evrazruda" developed by JSC "Giproruda" to maintain the enterprise's production capacity of 6 million tons per year, the shaft "Skipovoy" should be sunk from the level of $115 \mathrm{~m}$ to the level of $85 \mathrm{~m}$. Due to the fact that the reconstruction period was to be shortened, the employees of LLC "SibGorComplex Engineering" together with the Underground and Mine Construction Department of T.F. Gorbachev Kuzbass State Technical University developed several variants of new design of wedge pentices for vertical mine shaft sinking under hoisting operations. The results of studies of the dynamic loading impact on the design of safety devices in skip shaft sinking are presented in the article. Based on the method of designing the force action essentials for the emergency skip dumping, the functions allowing determining the value of the impact on the main structural elements of pentices completely bridging over the shaft cross-section that can be used to substantiate the design parameters of new wedge pentices.
\end{abstract}

\section{Introduction}

Vertical shafts and their sinking are the most important link in the construction and reconstruction of mines, since only after their completion there is an opportunity to perform development works on the next level to stope new reserves which are often richer in mineral content.

When sinking the active hoisting shaft, to protect workers in its sunk part from the possible fall of vehicles or their contents, it is necessary to construct safety devices that can completely bridge over the shaft cross-section or part of it and must withstand a heavy impact load, and also be strong, simple in design, require less labor for construction and subsequent dismantling $[1,2]$.

In each specific case, the structural elements of the pentice, the main of which are horizontal support beams, are designed on the basis of their designation and shaft sinking specifications. 
The analysis of the shaft sinking experience shows that in most design solutions it is proposed to use artificial horizontal pentices with a support element such as H-beam or truss structures completely bridging over the shaft cross-section.

The highest requirements for the design of the structural elements of pentices and their construction are required for skip-hoisting shaft sinking. This pentice must withstand the heavy dynamic impact in the event of the full skip run or the spillage of its contents, and the design - provide the possibility of construction in the shortest possible time in order to reduce the shaft stoppage time and avoid a decline in the enterprise's output capacity [3, 4].

In terms of the possible load on the pentices, skip shafts can be:

- unbalanced hoisting;

- multi-rope hoisting;

They are characterized by the following types of dynamic impact on the pentice:

- full skip run;

- emergency skip self-dumping.

Shafts of most modern mines are equipped with powerful multi-rope skip hoisting equipment. Simultaneous run of the ropes and drop of the full skip in this case is excluded, so, during the active hoisting shaft sinking, the pentice is constantly exposed to the impact of the separately falling pieces, and can also be subjected to dynamic impact of the rock mass flow in the event of an emergency skip dumping.

\section{Results}

Designing the pentice for the impact in the case of emergency self-dumping of skips when sinking the active hoisting shaft, we adopted a technique developed for the Krivbass mines, which makes it possible to determine the probabilistic value of the dynamic load of the rock mass flow onto the pentice completely bridging over the face on a level of the sunk part cross-section [5, 6] (Fig. 1)

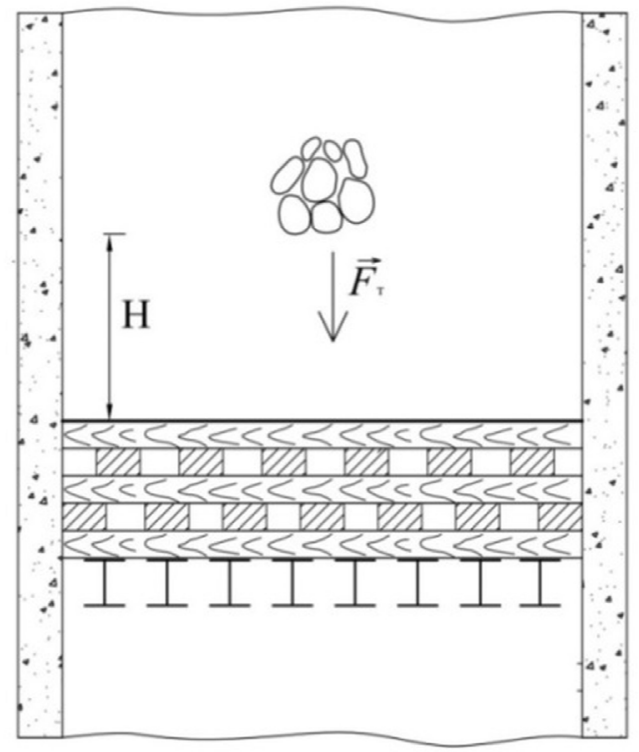

Fig. 1. Design scheme. 
Study of the dynamic loading impact on the pentice design have made it possible to determine the impact value as a function of the flow coefficient $\chi$ (Fig. 2, a), the fall velocity $V_{n m}$ (Fig. 2, b), and the height of body fall $H$ (Fig. 3, a), as well as determine the change in velocity $V_{n m}$ as a function of the height of body fall $H$ (Fig. 3, b). Taking into account that the speed of air far from the falling body is zero and the flow velocity near the body is about $100 \mathrm{~m} / \mathrm{s}$, we can conclude that the pressure difference by the Bernoulli theorem will be about $650 \mathrm{~kg}$ per square meter. In this case, the ratio between the pressure difference and the atmospheric pressure will be very small (about 6\%). Based on Boyle's law, this value characterizes the degree of compression, i.e. when the body falls at such a velocity, it can be assumed that the air near the body is practically incompressible.
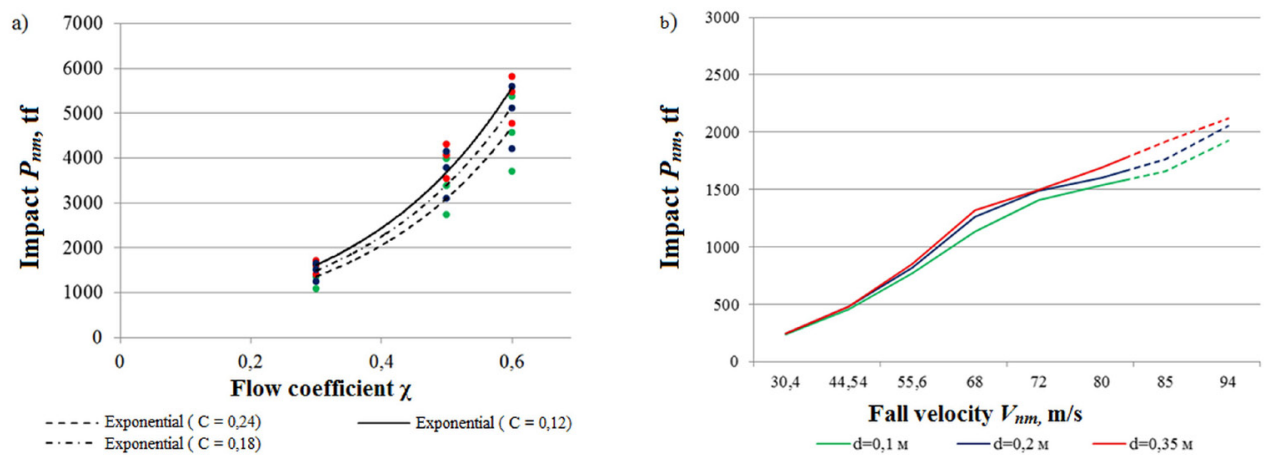

Fig. 2. The change in the impact volume Pnm as a function of the flow coefficient $\mathrm{X}$ (a) and the fall velocity $V n m$ (b) for the spillage of various size broken ore.

a)

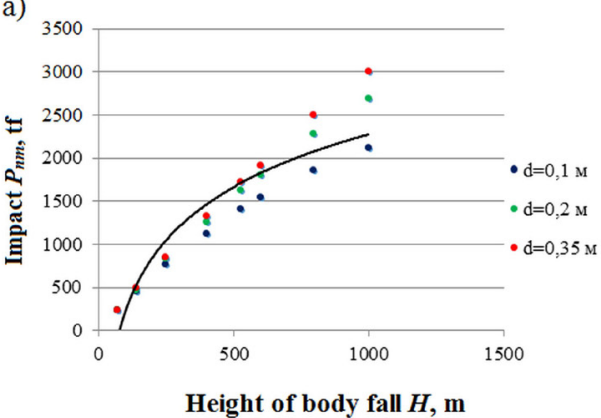

b)

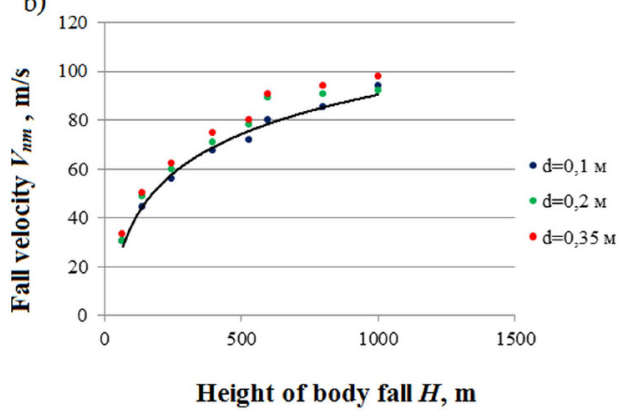

Fig. 3. The change in the impact volume Pnm (a) and the fall velocity Vnm (b) as a function of the height of body fall

On the basis of the obtained mathematical modeling results and the plotted functions, it is found that the value of the impact on the pentice increases exponentially (see Fig. 2, a). In turn, the dynamic load and the body fall velocity increase directly in proportion as a logarithmic function of the height of the fall (see Fig. 3). Thus, a change in the magnitude of the flow coefficient $\chi$, taken as a function of the broken ore size, affects the force of collision of the bodies against the impact volume. The optimum broken ore size is, in this case, a value not exceeding $0.2 \mathrm{~m}$ in diameter. 
Design of the impact volume elements using the method of determining the impact value in the shaft developed for the Krivbass mines show that for a complete bridging over of the sunk part of the shaft on a level of the cross-section, more labor and material consumption will be required, especially for the construction of horizontal support beams.

In order to reduce material resources and labor costs in the design and construction of pentices, it is necessary to take into account the purpose of the shaft and the size of the equipment layout in its cross-section.

In the process of the implementation of Gorno-Shorsky branch of JSC "Evrazruda" reconstruction project, the shaft "Skipovoy" should be sunk from the level of $115 \mathrm{~m}$ to the level of $85 \mathrm{~m}$ (sinking increment is $200 \mathrm{~m}$ ).

The shaft is designed to hoist ore with two $50 \mathrm{t}$ capacity skips of and two rock hoisting $15 \mathrm{t}$ capacity skips to provide the output of 6 million tons of ore mass per year (Fig. 4, a).

To sink the shaft from the $85 \mathrm{~m}$ level, which was previously tapped by the shaft "NovoKletevoy", the $2 \times 2 \mathrm{~m}$ raise was put down in its central part by drilling-and-blasting technique with the use of KPV-2 complex. Further full-face shaft sinking was carried out downward, repassing the rock through the raise to the $85 \mathrm{~m}$ level and the subsequent loading into the car VB-2,5 with the help of the rock-loading machine PPM-2

The study of the practice of constructing and using artificial pentices when sinking the vertical mine shafts shows that for the adopted flow sheet it is possible to use the design elements of the wedge pentices proposed by prof. Fedorov S.A., in which the dynamic impact on horizontal bearing beams is significantly reduced due to inclined impact plates $[7,8]$. In addition, compared to horizontal pentices designed to completely dissipate kinetic energy, the material consumption in the wedge pentices is less. Taking into account these advantages of the wedge pentices, and most importantly with the aim of minimizing the dynamic load impact on them detected during the mathematical modeling process (Fig. 2, Fig. 3), LLC "SibGorComplex Engineering" together with the Underground and Mine Construction Department of T.F. Gorbachev Kuzbass State Technical University developed several variants of new wedge pentice designs for active vertical hoisting shaft sinking, which are protected by utility patents $[9,10,11]$. They are a Z-shaped structure of upper and lower pentices height-shifted and parallel to each other, which, due to the inclination angles, serve as an impact wall (Fig. 4, b).

Bumper manifold weighting concrete slabs and timber damping elements lined with inclined impact metal plates are constructed on the support beams placed at the base of the pentices.

The upper and the lower parts of the pentices are interconnected by the separation wall, thereby completely bridging over the cross-section of the sunk part of the vertical shaft.

The upper pentice, designed to withstand heavy shock load, is mounted under the skip way. The lower part of the pentice designed for much less shock load is built under the compartment of rock skips which are smaller in size.

Industrial tests of the new design of the wedge pentices, developed and designed using the technique of dynamic impact on its main element - supporting beams, in case of emergency skip self-dumping confirmed its high reliability.

Shock loading as a result of the inevitable spillage of ore mass in the volume up to $40 \mathrm{~m}^{3}$ per day during the operation of skip hoisting and the mass of one piece reaching $200 \mathrm{~kg}$ is first is taken by the inclined plane of the upper pentice, then by the inclined plane of the lower pentice, which also take the load from the rock hoisting skips. Due to a change in the direction of movement of the falling ore and rock pieces, the impact load is tens of times smaller than when the kinetic energy of the bodies falling on the horizontal pentices is completely dissipated. 
a)

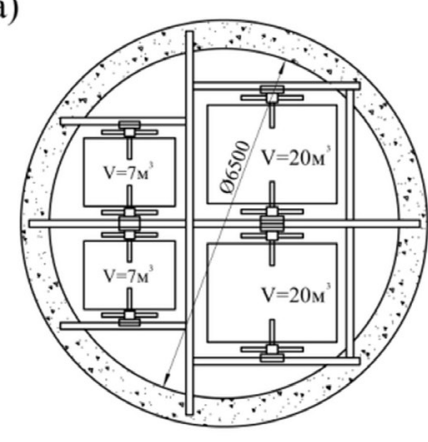

b)

)

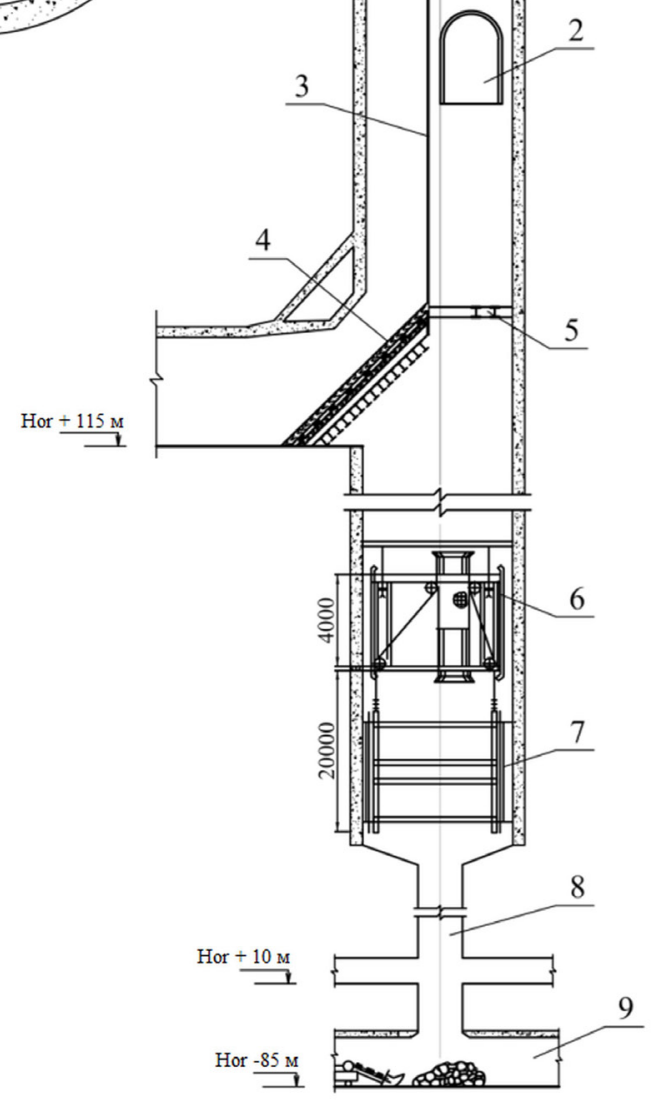

Fig. 4. The "Skipovoy" shaft sinking flowsheet: 1 - upper pentice, 2 - rope drift, 3 - separation wall, 4 lower pentice, 5 - sheave wheels platform, 6 - hanging scaffold, 7 -lining, 8 -raise, 9 -haulage roadway.

All the spillage slides into a special impact stable, in the capacity of which a design mine consisting of a complex of pit-bottom structures can be used.

The use of the new pentice design made it possible to ensure the reliable work safety when sinking the vertical shaft "Skipovoy" of the Gorno-Shorsky branch of OJSC "Evrazruda", to obtain an economic benefit of 70 million rubles by reducing the material consumption, the labor intensity of mounting, dismantling, and reducing the skip hoisting stoppage time [12$15]$. 


\section{Conclusion}

On the basis of the foregoing, it can be concluded that the issue of protecting the faces of sunk shafts is a rather complex and important stage in the reconstruction of a mine. It is particularly difficult to solve when sinking skip shafts. The construction and withdrawal of pentices in active hoisting shaft is a labor-intensive process requiring detailed coordination of the work on the protection of the face and the operational activities of the mine. The complexity of resolving this issue is due to two main reasons: construction of pentices tied to time allocated by the mine's maintenance department for stopping skip hoists for the period of installation of penthuses, as well as large probabilistic loads due to the increasing mining depth and skip load capacity. In this regard, there is a technical contradiction, on the one hand, the constantly increasing mining depth and the skip load capacity leads to the need to construct solid pentices, and on the other - the construction of solid pentices is timeconsuming, which causes shaft stoppage during their installation and mining losses. All this leads to significant labor, time and material costs.

The developed Z-shaped design of the wedge pentice and its modifications $[9,10,11]$, including the height-shifted elements of the upper and lower parts lined with the inclined impact plates interconnected by a vertical separation wall, allows manifold reducing the shock load impact by changing the body movement direction and dissipating its kinetic energy, in comparison with the construction of solid, horizontal pentices completely bridging over the shaft on a level of its sunk part cross-section.

Industrial tests of the new design of the предохранительного полка when sinking the vertical shaft "Skipovoy" of the Gorno-Shorsky branch of OJSC "Evrazruda" confirmed its high reliability, efficiency and safety with a reduction in the material consumption. The proposed design has made it possible to reduce the material consumption and labor intensity of installation and dismantling in comparison with solid horizontal pentices.

\section{References}

1. V. A. Kovalev, A. I. Kopytov, V. V. Pershin, Coal, 2, 6 (2014)

2. Federal Regulations for industrial safety «Safety rules for coal mines» (Scientific and Technical Center for Research of Industrial Safety Problems, Moscow, 2014)

3. Uniform safety rules for underground mining of ore, non-ore and placer mineral deposits: Safety Rules 03-553-03 (Research and Engineering Center, Moscow, 2003)

4. V. V. Pershin, A. I. Kopytov, V. I. Sarychev, Vertical shaft tunneling and sinking: university textbook (Science, Moscow, 2014)

5. Instruction for design, construction and dismantling of safety devices for vertical shaft sinking (IMPT, Kharkov, 1979)

6. Temporary instruction for the protection of the faces of vertical shafts of operating mines (USSR Ministry of ferrous metallurgy, Moscow, 1985)

7. S. A. Fedorov, Shaft sinking (State Mining Publishing, Moscow, 1963)

8. V. V. Smirnyakov, V. I. Vikharev, V. I. Ochkurov, Mine construction technology: university textbook (Nedra, Moscow, 1989)

9. A. I. Kopytov, I. V. Zhuk, M. D. Voitov, S. S. Morozov, Utility patent № 120706 "Wedge pentice when sinking the vertical mine shaft» (Rospatent, Moscow, 2012)

10. I. V. Zhuk, A. I. Kopytov, V. V. Pershin, M. D. Voitov, A.A. Wetti, Utility patent № 133198 «Wedge pentice» (Rospatent, Moscow, 2013) 
11. A. I. Kopytov, M. D. Voitov, A. A. Wetti, Utility patent № 139338 «Wedge pentice» (Rospatent, Moscow, 2014)

12. A. I. Kopytov, M. D. Voitov, A. A. Wetti, Mining Journal, 1, 67 (2015)

13. V. V. Pershin, A. I. Kopytov, M. D. Voitov, I. V. Zhuk, A. A. Wetti, Taisan Academic Forum - Project on mine Disaster Prevention and Control, 21 (2014)

14. A. I. Kopytov, V. V. Pershin, M. D. Voitov, A. A. Wetti, The 8th Russian-Chines symposium coal in 21 st century: mining, processing and safety, 108 (2016)

15. I. A. Ermakova, Journal of Mining and Geotechnical Engineering, 1, 4-10 (2018) DOI: 10.26730/2618-7434-2018-1-4-10 